\title{
Interannual variability of moistening in the European Russia
}

\author{
V. N. Malinin ${ }^{1}$, S. M. Gordeeva ${ }^{1}$, Yu. V. Mitina ${ }^{1}$, and A. V. Kuleshova ${ }^{1}$
}

Received 5 November 2020; accepted 21 December 2020; published 13 May 2021.

The article discusses the features of large-scale spatial and temporal variability of moistening (potential evapotranspiration, precipitation, potential evapotranspiration coefficient) in the European Russia (ER) for 1966-2017. Much attention is paid to abnormal moistening conditions (droughts and excessive moistening) resulting in significant ecological and economical damage. The All-Russia Research Institute of Hydrometeorological Information archive has served as a source of initial information. The most physically based modified method of M. I. Budyko has been used to estimate the potential evapotranspiration. A series of original maps of components of moistening has been constructed, a number of maps for the ER being constructed for the first time. The presence of positive trends in the annual values of potential evapotranspiration and precipitation has been established, the distribution of which being patchy. The highest trends have been noted in the southern European Russia, the distribution of positive trends in potential evapotranspiration being patchy as well, with minimum estimates of $3.7 \mathrm{~mm}$ per year in the Syktyvkar area. Due to the similar trend character in potential evapotranspiration and precipitation there takes place the smoothening in potential evapotranspiration coefficients resulting in their trends being statistically insignificant over most of the ER. The interannual variation of components of moistening is characterized by the presence of powerful anomalies in the form of extreme droughts and excessive moistening. Their formation is due to the complete coincidence of significant positive potential evapotranspiration anomalies and negative precipitation anomalies in most of the ER, and vice versa. Unevenness has been revealed in the spatial distribution of severe droughts and excessive moistening of the territory: the most powerful droughts are concentrated mainly in the forest-steppe zone (with maximum in the Krasnoslobodsk and Elatma regions). Excessive moistening is predominantly patchy in nature, being practically absent in the northern regions of the ER. A decrease in potential evapotranspiration has appeared to be the predominant factor in the formation of excessive moistening, a decrease in precipitation being the one in the formation of droughts. KEYWORDS: Potential evapotranspiration; precipitation; moistening; European Russia; drought; trend.

Citation: Malinin, V. N., S. M. Gordeeva, Yu. V. Mitina, and A. V. Kuleshova (2020), Interannual variability of moistening in the European Russia, Russ. J. Earth. Sci., 21, ES3001, doi:10.2205/2020ES000753.

\footnotetext{
${ }^{1}$ Russian State Hydrometeorological University, St. Petersburg, Russia

Copyright 2020 by the Geophysical Center RAS. http://rjes.wdcb.ru/doi/2020ES000753-res.html
}

\section{Introduction}

In general, absolute moistening is considered to be the difference between the amount of precipitation fallen $(P)$ and the total evaporation from the 
underlying surface $(E)$, being the link between the water balances of the atmosphere and the land surface and most objectively characterizing the degree of aridity (excessive moistening) of the land surface [Smirnov and Malinin, 1988. Indeed, if $E>P$ for a long time, this leads to depletion of water reserves in the soil and, as a consequence, to the formation of droughts. On the contrary, if $P>E$ for a long time, excessive moistening is noted. An integral indicator of the land surface moistening is the annual runoff of large rivers, which smoothens landscape factors and reflects mainly the effect of climatic factors. For sufficiently large river basins, the absolute moistening over a long-term period corresponds to the river runoff at the outlet section. Although, due to the multifactorial nature of the evaporation formation from various landscapes, the spatial variability of evaporation is significantly higher than the one of precipitation, its temporal variability, on the contrary, being much less. This makes it possible to build statistical models of annual and spring runoff of large rivers in the European Russia based only on precipitation data for previous periods of time [Gordeeva and Malinin, 2018, Malinin and Gordeeva, 2019, Popova et al., 2019.

When assessing the absolute moistening $(P-E)$, the greatest difficulty is to determine the total evaporation, especially for large areas consisting of a combination of different types of land surface: forests, meadows, agricultural fields, reservoirs, stream channels, swamps, urbanized areas, transpiration of vegetation cover, etc. The integral accounting of all types of evaporation is obviously possible only when the equation of water balance of river basin or atmosphere is closed. As a result, the total evaporation estimate will include all errors of other balance components.

Due to complexity of accounting for individual evaporation types, the calculations often use semiempirical relationships between total evaporation and its determining factors. The value of potential evapotranspiration $\left(E_{0}\right)$, which is usually understood as the maximum possible evaporation under given meteorological conditions, when soil moisture does not have a limiting effect on the evaporation, is especially often used for this purpose.

Potential evapotranspiration is a basis for assessing different indices of moistening: potential evapotranspiration coefficient $E_{0} / P$, relative evaporation $E / E_{0}$, evaporation deficit $E_{0}-E$, etc. [Zubenok,
1976. The most universal index is considered to be the coefficient of potential evapotranspiration $E_{0} / P$, which, through various semi-empirical equations, is directly related to $P-E$, total evaporation $E$ and other humidification characteristics. For example, the equation of the relationship between the water balances of the atmosphere and the land surface has in general the following form [Smirnov and Malinin, 1988:

$$
\frac{E-P}{P}=\varphi \frac{E_{0}}{P}
$$

where $\varphi$ is a function dependent on a geobotanical zone. This expression has three features:

1. it reflects the interconnection of parameters that cause moistening;

2. the $E-P$ difference enters simultaneously into the balance equations of the atmospheric and terrestrial branches of the hydrological cycle, thus linking the transport of moisture in the atmosphere with the processes of water movement in the soil-ground mass;

3. it is carried out at sufficiently large spatial and temporal averaging scales, when the total evaporation is determined mainly by climatic factors, while the role of local (landscape) factors is negligible. The specific form of the function $\varphi$ is given in [Malinin, 1994. Smirnov and Malinin, 1988.

At present, under the conditions of global warming, accompanied by imbalance in the climate system, there occurs a sharp increase in abnormal conditions of absolute moistening of the land surface, primarily droughts and excessive moistening, including floods. The negative environmental aspects of droughts include: deterioration in the quality of atmospheric air and public health, increased forest fires, burning peatlands, depletion and pollution of land waters, disruption of bio-equilibrium in the natural environment, a significant reduction in the yield of many crops, etc. The negative environmental aspects of excessive moistening are: inundation and waterlogging of settlements, agricultural lands, bogging of the area, a significant reduction in the yield of many crops, etc.

It is droughts and floods that make the greatest contribution to the rapid growth of extreme hydrometeorological events (hydrometeorological hazards, $\mathrm{HH}$ ), leading to significant environmental and 
economic damage $[I P C C, 2013,2019]$. In particular, for the territory of Russia, over a period of only 17 years (1996-2012), the growth of such events occurred at a rate of 188 per 10 years, resulting in more than doubling of their number [Frolov, 2014]. It should be noted that the impact of hydrometeorological hazards on the sustainable development of the Russian economy is significant and amounts to many tens of billion roubles. [Bedritskii et al., 2009, Rybanova et al., 2019. A detailed description of droughts over the past half century in the ER is presented in [Cherenkova, 2013. A weak negative trend in the moistening of arid lands in the southern ER in the first decade of the 21st century is noted in [Zolotokrylin et al., 2014].

Revealing the genesis of interannual variability and, specifically, the construction of models for a long-term forecasting of the characteristics of moistening and river runoff under the conditions of modern climate change is not only a fundamental scientific problem, but is also of great ecological and economic importance. The aim of the paper is to identify the features of the spatial and temporal variability of the moistening characteristics in the ER with an emphasis on severe droughts and excessive moistening of the territory.

\section{Materials and Methods}

The RIHMI-WDC archive (http://aisori.meteo. $\mathrm{ru} /$ ClimateR), containing data of current instrumental observations of almost 500 meteorological stations in Russia, mainly since 1950, when the network of stations rapidly increased, has served as a source of initial information to assess the characteristics of moistening. The archive provides access to data on the amount of precipitation, atmospheric pressure, sunshine, water vapour pressure, daily air temperatures and precipitation, daily data on soil temperature, snow cover characteristics. This archive has provided precipitation time series since 1966, when the transition to the Tretyakov rain gauge was completed at meteorological stations and a wetting correction began to be introduced. Since 1966, there have been no changes in the measuring and processing techniques, so the series of precipitation amounts can be considered homogeneous [Bulygina et al., 2020]. We used the data on precipitation at stations located in the ER north of $45^{\circ} \mathrm{N}$, the lowest network density being noted for the north-eastern ER.

For average long-term monthly conditions, a comprehensive method for assessing the potential evapotranspiration by M. I. Budyko [Budyko, 1971] is considered the most recognized and physically grounded, since it takes into account the main factors determining $E_{0}$ : radiation balance, air temperature and humidity. It is based on the idea of proportionality of evaporation from a wet surface to moisture deficit, determined by the temperature of the evaporating surface. The fundamental disadvantage of the method is that it can only be used to calculate the long-term monthly average values of $E_{0}$. A comparative analysis of contribution of individual elements to the value of $E_{0}$ shows that the influence of cloudiness, used to determine the radiation balance, can be neglected, temperature and humidity being related through a moisture deficit d. Consequently, potential evapotranspiration can be expressed in terms of moisture deficit.

To determine $E_{0}$ for specific monthly intervals, one can use the hypothesis of the conjugation of space-time fluctuations in potential evapotranspiration and moisture deficit [Malinin, 1994], according to which the potential evapotranspiration in a specific $i$-th month at the $j$-th station is determined as:

$$
E_{0 i j}=\bar{E}_{0 j}\left(\frac{d_{i j}}{\bar{d}_{j}}\right)^{\chi}
$$

where $\bar{E}_{0 j}$ and $\bar{d}_{j}$ are the average long-term values of potential evapotranspiration and moisture deficit at the $j$-th station respectively. At the same time, the average long-term value of potential evapotranspiration at the $j$-th station can be expressed as:

$$
\bar{E}_{0 j}=<\bar{E}_{0}>\left(\frac{\bar{d}_{j}}{<\bar{d}>}\right)^{\chi}
$$

where the triangular brackets denote spatial averaging, the parameter $\chi$ being the ratio of the spatial (temporal) coefficients of variation $(C)$ of potential evapotranspiration and moisture deficit, i.e.

$$
\chi=\frac{C_{<E_{0}>}}{C_{<d>}}=\frac{C_{E_{0 i}}}{C_{d i}}
$$

This formula implies that the temporal variability of monthly average parameters of potential 
Table 1. Seasonal Variation of the $\chi$-Coefficients for Various Geobotanical Zones of the European Russia for 1966-1995 According to [Malinin et al., 2014]

\begin{tabular}{lccccccc}
\hline Geobotanical zone & April & May & June & July & August & September & October \\
\hline Coniferous forests & 0.74 & 0.66 & 0.39 & 0.39 & 0.48 & 0.68 & 0.74 \\
Mixed and deciduous forests & 0.56 & 0.41 & 0.37 & 0.38 & 0.47 & 0.62 & 0.56 \\
Forest steppe & 0.52 & 0.40 & 0.36 & 0.37 & 0.42 & 0.62 & 0.52 \\
Steppe & 0.56 & 0.46 & 0.39 & 0.40 & 0.46 & 0.57 & 0.56 \\
\hline
\end{tabular}

evapotranspiration and moisture deficit at a particular point of the ER is equivalent to the spatial variability of the average long-term values of the same parameters. Therefore, the formula (1) represents the desired solution to the problem of determining the potential evapotranspiration for short (monthly) time intervals. It is worth noting that the proposed approach is quite simple and does not require knowledge of any parameters that are difficult to determine.

For calculations to be convenient, parameterization of the long-term average values of potential evapotranspiration has been carried out. For this purpose, the nomograms of their dependence on moisture deficit, built on the basis of an integrated method and presented in [Gidrometeoizdat..., 1976, have been used for various geobotanical zones of the ER and for each month of the warm period (April-October). The potential evapotranspiration values obtained in digital form have been used to approximate the dependence $\bar{E}_{0}=f(\bar{d})$ with various empirical formulas. The most universal function has been found to be the rational one [Malinin et al., 2014, providing the maximum accuracy of the potential evapotranspiration approximation and having the following form:

$$
\bar{E}_{0}=\frac{a_{0}+a_{1} \bar{d}}{1+a_{2} \bar{d}+a_{3} \bar{d}^{2}} .
$$

For each month of the warm (April-October) period and for various geobotanical zones of the ER, the coefficients of the rational function have been determined, the coefficient of determination reaching $R^{2}=0.99$ in all cases. Since the potential evapotranspiration is assumed to be equal to evaporation from snow in the winter (November-March) period, the formula $E_{\text {win }}=0.37 n \times d$ can be used to estimate its average monthly values, where $n$ is the number of days in a month. For October, the April values of $\chi$ are used. Therefore, the annual cycle of potential evapotranspiration can be determined only from data on the moisture deficit values.

Using the average long-term monthly values of potential evapotranspiration, it is easy to estimate the coefficients $\chi$, presented in Table 1 for different geobotanical zones of the ER. An extremely seasonal variation in their distribution is clearly seen, with a minimum being in June and a maximum range of fluctuations referring to coniferous forests.

The calculation of $E_{0} / P$ values has been carried out for 1966-2017 period according to the data on the water vapour elasticity, air temperature and precipitation at meteorological stations located rather evenly over the ER. A very laborious work was previously performed to prepare the initial data for calculating the monthly average $E_{0} / P$ values. For this purpose, the meteorological characteristics were selected from the database for each period ( 8 times a day) at 125 stations. For each station, according to the air temperature, using the Magnus formula, the saturating water vapour pressure $e_{S}$ was determined. After that, the average daily moisture deficit $\left(d=e_{S}-e\right)$ was calculated. Further, the monthly average deficit values were found, serving as a basis for all subsequent calculations. Some observation series appeared to have significant gaps. The stations having less than $5 \%$ gaps in the current summer data on average for the entire period, were selected. For them, the monthly average values were calculated as a weighted average relative to the number of qualitative observation periods. If the number of gaps per month exceeded $50 \%$, the monthly average was not calculated and was considered as a gap in the average monthly row. When averaged over half a year and 
over a year, such gaps were filled with average values for that season. The final number of stations used in subsequent calculations amounted to 47 . When constructing the maps, the latitude of $45^{\circ} \mathrm{N}$ was taken as the southern boundary of the ER.

\section{Results and Discussion}

As a result of the calculations, a series of original maps has been built: maps of total potential evapotranspiration, variation coefficients and linear trends of potential evapotranspiration, total precipitation, variation coefficients and linear trends in precipitation, potential evapotranspiration coefficient, its coefficient of variation and linear trend. Maps have been built over a long-term (1966-2017) period in three versions: for the cold (October-March) and warm (April-September) periods and on average for a year, a number of maps for the ER being built for the first time.

Naturally, in this paper we cannot provide the results of analysis of all maps. Figure 1 a shows the distribution of the average long-term values of potential evapotranspiration, precipitation, and potential evapotranspiration coefficient over the ER. A gradual increase in potential evapotranspiration from northern to southern latitudes is easily seen. The minimum $E_{0}$ values are noted in the YamaloNenets Autonomous District (about $400 \mathrm{~mm}$ ), the maximum values observed in the Astrakhan region (about $1000 \mathrm{~mm}$ ).

As expected, these results have turned out to be quite close to the map of potential evapotranspiration constructed by L. I. Zubenok in 1976 using the Budyko method for the USSR territory [Zubenok, 1976]. The differences are mainly due to the fact that our data are somewhat higher for most of the ER, which is associated with noticeable warming of the territory under consideration. In the far north, this increase is up to $100 \mathrm{~mm}$. To the south, the differences become predominantly patchy. In the south-western regions of the ER, they are higher than in the eastern ones. Note that the paper [Cherenkova and Shumova, 2007 compared the long-term average values of $E_{0}$ calculated using 13 different methods, which showed significant discrepancies between them. According to the authors, the Thornthwaite method, using only the air temperature data, is preferable. However,
Zubenok 1976 convincingly proved a significant underestimation of $E_{0}$ estimates by the Thornthwaite method compared to the complex Budyko method, which is confirmed by the map in Figure 1a.

The distribution of average long-term annual values of potential evapotranspiration within the ER is revealed to have an exponential dependence on the air temperature:

$$
E_{0}=456.81 \exp (0.058 T) .
$$

The determination coefficient of this dependence is $R^{2}=0.80$, the root-mean-square error being $\sigma=54.8 \mathrm{~mm}$, i.e. it allows to obtain approximate estimates of $E_{0}$. However, the time dependence of the annual potential evapotranspiration values averaged over the ER on air temperature is in a narrower temperature range and therefore has a linear character. With an increase in temperature by $1^{\circ} \mathrm{C}$, the potential evapotranspiration rate increases by $28.5 \mathrm{~mm}$. At the same time, the increase in potential evapotranspiration decreases from semi-deserts of the extreme south $\left(57.2 \mathrm{~mm}\right.$ per $\left.1^{\circ} \mathrm{C}\right)$ towards tundra of the extreme north $\left(15.5 \mathrm{~mm}\right.$ per $\left.1^{\circ} \mathrm{C}\right)$.

Figure 1b gives a map of the spatial distribution of annual precipitation amounts over the ER. In general terms, it agrees with the earlier Schwer's map [Schwer, 1976] compiled from climatological data for 1936-1970. A clearly pronounced decrease in precipitation from the north-western to southeastern ER is noted. The maximum precipitation is observed in the region of Smolensk-Toropets, and the minimum one - in the Lower Volga. Another maximum of precipitation is confined to the foothill of the Ural Ridge. The average long-term (for 1966-2017) amount of precipitation over the ER amounts to $562 \mathrm{~mm}$. According to the estimate given in [Frolov, 2014, the precipitation rate over the EP for 1961-1990 is $556 \mathrm{~mm}$.

Figure 1k shows the spatial distribution of the average annual values of the potential evapotranspiration coefficient. Comparison of this map with a similar one given in [Smirnov and Malinin, 1988] shows a shift in the $E_{0} / P$ estimates to the north, due to climate warming, which is especially significant in the southern ER. For example, in the Volgograd region this increase amounts to 0.4. The annual norms of $E_{0} / P$ allow to distinguish objectively the climatic zones by the nature of moistening [Smirnov and Malinin, 1988. When $E_{0} / P<$ 
a)

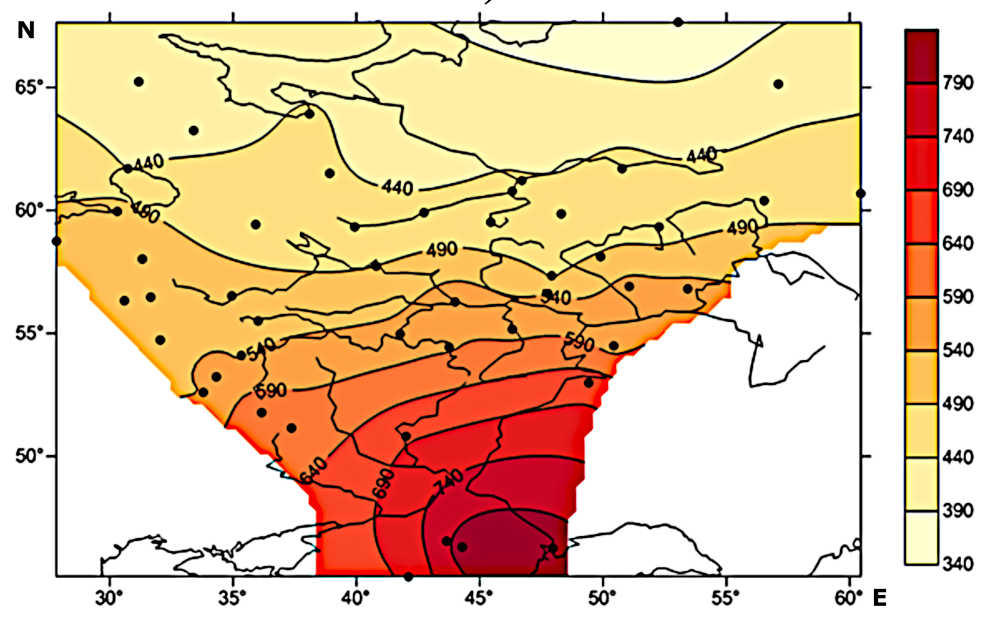

b)

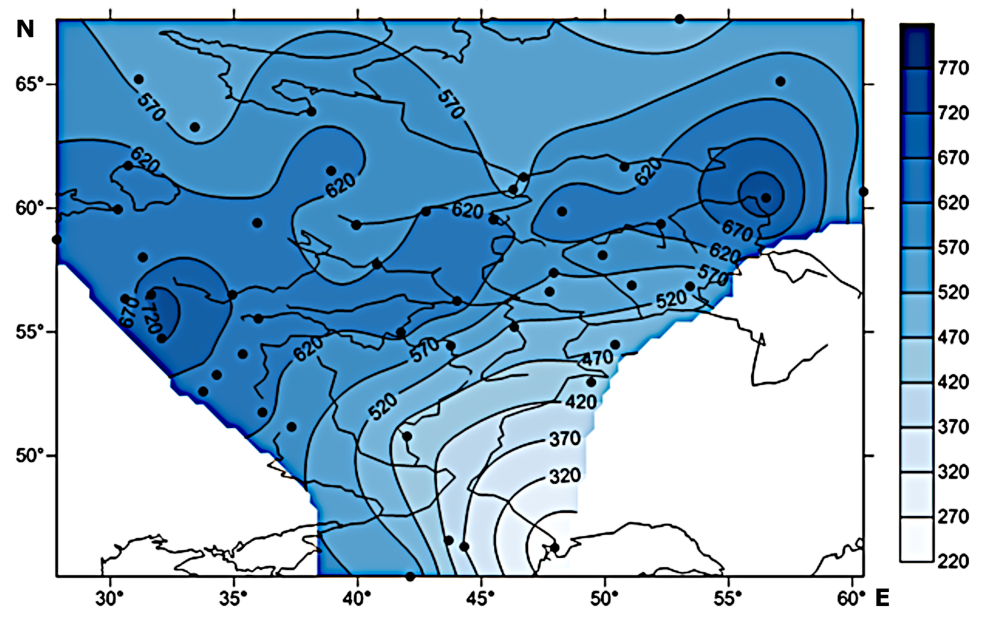

c)

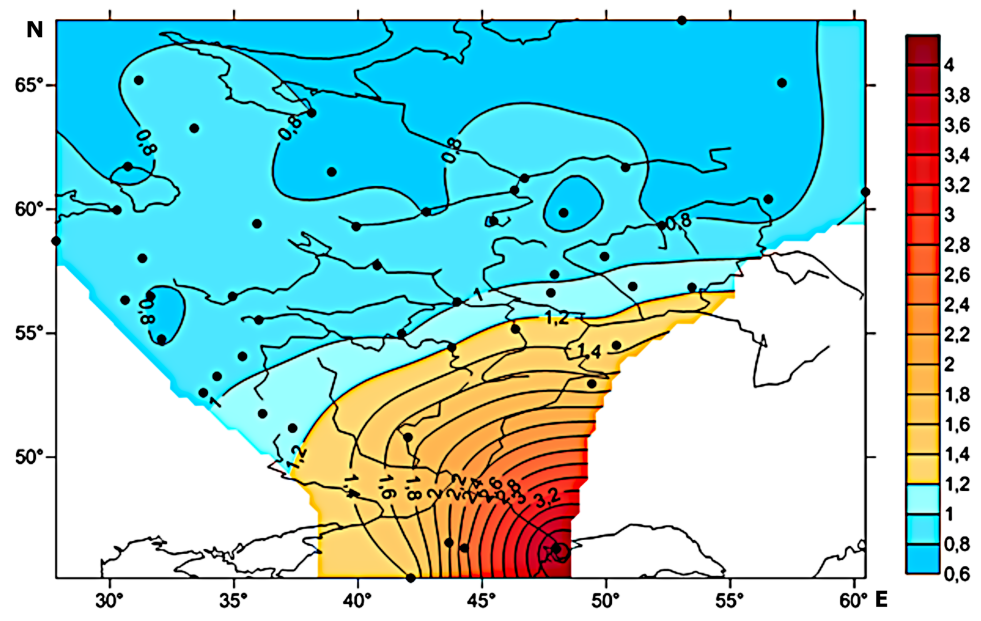

Figure 1. Spatial distribution of average long-term sums of annual values of potential evapotranspiration (a), precipitation (b) in $\mathrm{mm}$ and potential evapotranspiration coefficient (c) for 1966-2017 over the European Russia north of $45^{\circ} \mathrm{N}$. 


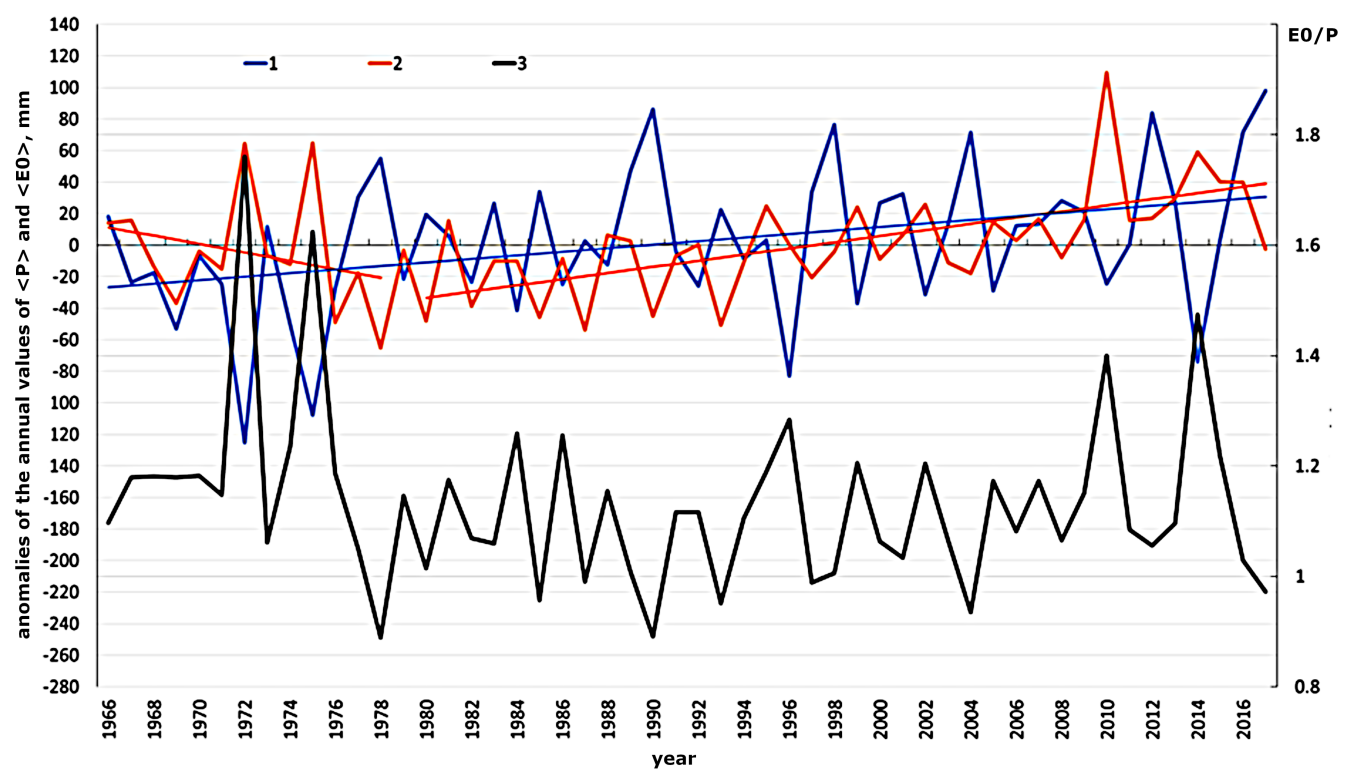

Figure 2. Interannual variation of anomalies of the annual values of $\langle P\rangle(1),\left\langle E_{0}\right\rangle$ (2), and $\left\langle E_{0} / P>(3)\right.$ averaged over the European Russia north of $45^{\circ} \mathrm{N}$ for $1966-2017$.

0.80 there is a zone of excessive moistening; when $0.80<E_{0} / P<1.00$ there is sufficient moistening; when $1.00<E_{0} / P<1.34$ there is variable moistening; when $1.34<E_{0} / P<1.60$ there is insufficient moistening; when $>1.60$ there is arid moistening. In 1994, the paper [United Nations Convention..., 1994 adopted a similar estimate of arid moistening $\left(E_{0} / P>1.54\right)$. Figure 1. shows that a large (northern and central) part of the ER is located in the zone of excessive and sufficient moistening. South of the isoline of $E_{0} / P=1.40$, the aridity of the territory rapidly increases. As expected, it reaches its maximum in the Lower Volga in the Astrakhan region. The long-term average value of the potential evapotranspiration coefficient is $\left\langle E_{0} / P\right\rangle=1.13$. Approximately two-thirds of the ER are located in the zones of excessive and sufficient moistening.

It has been established that positive values of linear trend in the annual potential evapotranspiration values are observed throughout the ER, the distribution of which being of a patchy nature. However, significant trends at a significance level of $\alpha=0.05$ are mainly confined to the southwestern ER. The maximum trend estimate is observed in the Bryansk region $(2.5 \mathrm{~mm} /$ year$)$, which corresponds to an increase in $E_{0}$ by $125 \mathrm{~mm}$ during 1966-2017. The location of positive trends in precipitation is confined to the Vychegda catch- ment area and north-western Russia, with significant maximum estimates of $3.7 \mathrm{~mm} /$ year being for the Syktyvkar region. Due to the similar nature of trends in potential evapotranspiration and precipitation, there happens smoothening of the potential evapotranspiration $E_{0} / P$ coefficients, resulting in their being insignificant in most of the ER, i.e. deviating from zero in random manner. An exception is the area around Syktyvkar, where the $E_{0} / P$ trend is negative and significant.

Let us now turn to Figure 2, which shows the interannual variation of the annual values of $\left\langle E_{0}\right\rangle$, $\langle P\rangle$ and $\left\langle E_{0} / P\right\rangle$ averaged over the territory under consideration for 1966-2017. The potential evapotranspiration is characterized by a decrease until 1978, followed by its rather rapid growth. The trend magnitude for 1979-2017 is almost $2 \mathrm{~mm} /$ year, while for the entire period under consideration it is $0.88 \mathrm{~mm} /$ year. The coefficient of variation, characterizing the interannual fluctuations $\left\langle E_{0}\right\rangle$, equals to $C_{v}=0.06$, several significant positive extremes being noted. These are 1972, 1975 and 2010. Negative anomalies in $<E_{0}>$ fluctuations are less pronounced. Annual $<E_{0}>$ estimates fully characterize their variability for the warm half of the year (correlation is $r=1.0$ ).

The interannual variation of precipitation is characterized by a significant positive trend, the value 


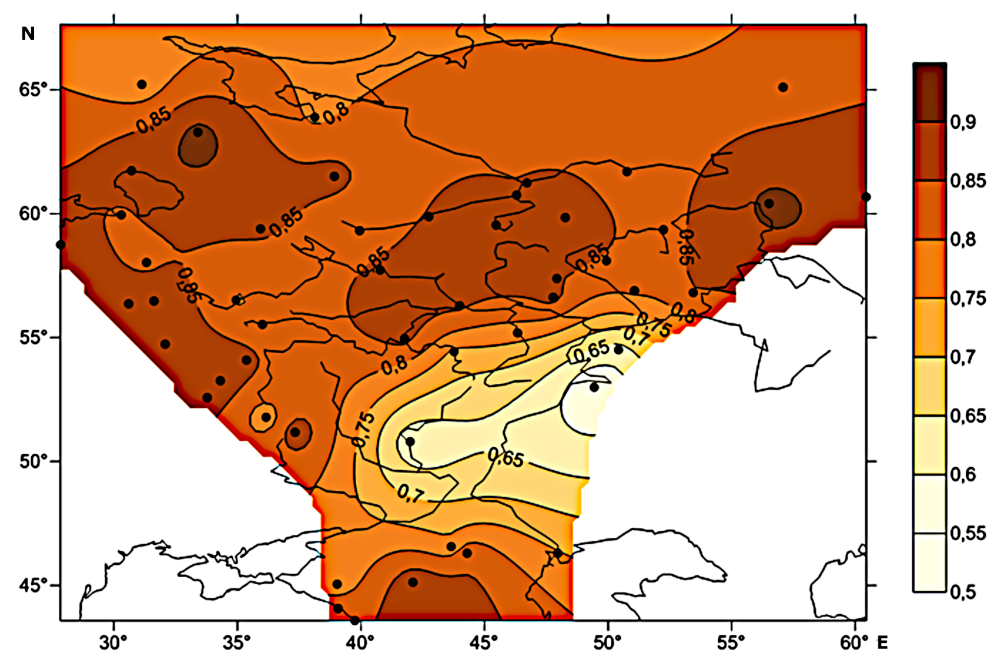

Figure 3. Distribution of linear contribution of precipitation to variability of summer $E_{0} / P$ values over the ER for $1966-2016$.

of which is $1.0 \mathrm{~mm} /$ year. The variability of $\langle P\rangle$ is slightly higher than the variability of $\left\langle E_{0}\right\rangle$ $\left(C_{v}=0.08\right)$. A characteristic feature of $\langle P\rangle$ is the presence of powerful anomalies. Negative extreme precipitation values are noted in 1972, 1975, 1996 and 2014, significant positive anomalies being noted in 1989, 1998, 2004, 2012 and 2017. The correlation of annual precipitation totals with precipitation for the warm half of the year is $r=0.66$. The correlation between $\left\langle E_{0}\right\rangle$ and $\langle P\rangle$ is not so significant $(r=-0.36)$, but there is a complete coincidence of significant positive anomalies $\left.<E_{0}\right\rangle$ with negative $\langle P\rangle$, and vice versa. This significantly increases the interannual fluctuations of $\left\langle E_{0} / P\right\rangle($ Figure 3$)$. The coefficient of variation almost doubles $\left(C_{v}=0.13\right)$. In terms of area coverage, the most severe droughts in the ER were recorded in 1972 and 1975, followed by 2015, 2010 and 1996 in terms of decreasing aridity. At the same time, a number of years with excessive moistening of the territory can be noted. Taking as the threshold the $\left\langle E_{0} / P>\right.$ value less than 1, we get: $1978,1985,1987,1990,1993,1997,2004$, and 2017. The correlation of $\left\langle E_{0} / P\right\rangle$ with $\left\langle E_{0}\right\rangle$ is $r=0.75$, and of $\left\langle E_{0} / P\right\rangle$ with $\langle P\rangle$ is $r=-0.84$, i.e. their influence on the $\left\langle E_{0} / P\right\rangle$ variability is almost the same. In contrast to potential evapotranspiration and precipitation, there is no trend in the interannual variation of $\left\langle E_{0} / P\right\rangle$. The correlation of annual $\left\langle E_{0} / P\right\rangle$ values with the potential evapotranspiration coefficient for the warm half of the year is $r=0.84$. Without using any additional criteria, the $\left\langle E_{0} / P\right\rangle$ series is clearly divided into 3 classes: above the norm, i.e. drought (5 years), below the norm (8 years) and the norm (39 years).

It is clear that the interannual variability of $E_{0} / P$ is completely determined by the variability of precipitation in the winter half-year. In the summer half-year, its interannual variability is less than the interannual variability of precipitation despite the fact that the absolute value of potential evapotranspiration exceeds precipitation. Therefore, the contribution of precipitation to the interannual variability of $E_{0} / P$ should be significantly higher. Using regression analysis in a linear approximation, maps of contribution of precipitation to the variability of the total values of $E_{0} / P$ for the warm period for 1966-2017 have been constructed. Indeed, for most of the ER, Figure 3 shows that it exceeds $80 \%$ in the latitudinal zone $53-63^{\circ} \mathrm{N}, R^{2}=0.85-0.90$. And only in the southeastern ER (in the Lower Volga region) it decreases to $R^{2}=0.55-0.70$.

Land moistening is very important for identifying and predicting droughts. Figure 2 shows the most powerful drought of 1972 , which lasted the entire summer season and covered almost the entire ER. Figure 4 gives a map of spatial distribution of the potential evapotranspiration coefficient for the summer (April-October) half-year of 1972 to its average long-term values. It was only in the 


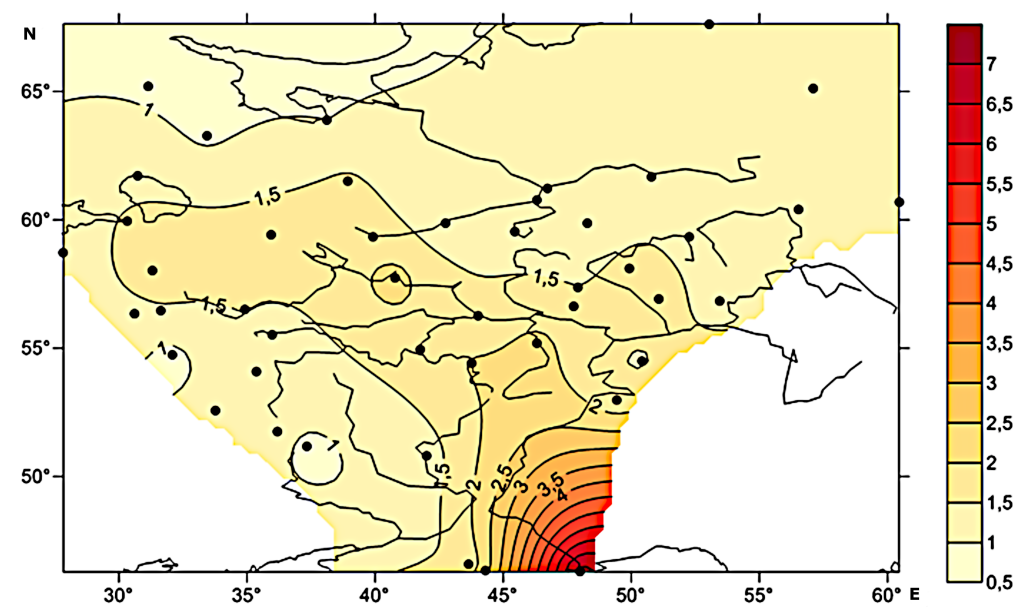

Figure 4. Spatial distribution of the ratio of the potential evapotranspiration coefficient for the summer (April-October) half-year of 1972 to its average long-term values.

extreme north-western ER that the drought was absent. Towards the southeast, the aridity of the territory increased, the $E_{0} / P$ norm being significantly exceeded from 1.5 to 2.5 times in most of the ER. Aridity increased especially rapidly south of Volgograd in the Lower Volga. In the Astrakhan region, it exceeded the norm by a factor of 6.5 . In April-October 1972, precipitation here amounted to $18.4 \mathrm{~mm}$, average annual value being $134 \mathrm{~mm}$.

Let us estimate the degree of unevenness of the spatial distribution of severe droughts and excessive moistening of the territory. For each station, the $E_{0} / P$ data were sorted into 3 samples: droughts (5 years), excessive moistening (8 years), and normal moistening (39 years). After that, for each station, a comparison of the average values in extreme years and years with normal moistening was carried out according to the Student's test

$$
\begin{gathered}
t=\frac{\bar{x}-\bar{y}}{\sqrt{(m-1) s_{x}^{2}+(n-1) s_{y}^{2}}} \times \\
\sqrt{\frac{m n(m+n-2)}{m+n}},
\end{gathered}
$$

where $\bar{x}, \bar{y}, s_{x}^{2}$ and $s_{y}^{2}$ are sample estimates of the average values and variances of the first and second samples, respectively; $m$ and $n$ are the lengths of the first and second sample, respectively. At the significance level of $\alpha=0.05, t_{c r}=1.96$. That is, for $t>2$, the discrepancies between the sample means are considered significant. This made it possible to construct maps of the spatial distribution of the Student's test, which characterizes the significant discrepancies in the average values of the potential evapotranspiration $E_{0} / P$ coefficient of droughts and excessive moistening from the norm (Figure 5).

Figure 5 a shows severe droughts to occur over most of the ER, the exception being the northern regions, north of $62^{\circ} \mathrm{N}$. The most powerful droughts are concentrated mainly in the forest-steppe zone (maximum in the Krasnoslobodsk and Elatma regions). The maximum estimates of the Student's test here exceed the critical value of $t_{c r}$ by almost 4 times. A more complex picture is observed in the spatial distribution of the Student's test, which characterizes significant discrepancies between the average values of the potential evapotranspiration $E_{0} / P$ coefficient and the norm during periods of excessive moistening. Figure $5 \mathrm{~b}$ shows that most excessive moistening is predominantly patchy in nature and is practically absent in the northern ER. There are four centres of excessive moistening, but their power is significantly inferior to severe droughts. Note that the "excessive moistening" of the south-eastern ER is relative, because even in the Lower Volga $t>t_{c r}$, being due to small amount of precipitation falling here. Therefore, even a relatively small excess of them over the norm significantly reduces the potential evapotranspiration coefficient estimate.

In conclusion, let us estimate the contribution of potential evapotranspiration and precipitation 
a)

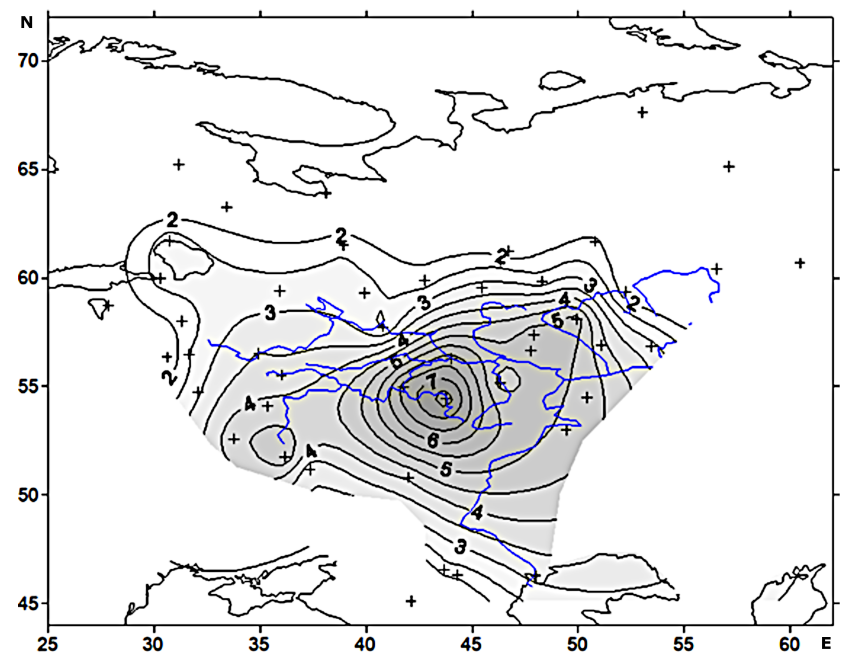

b)

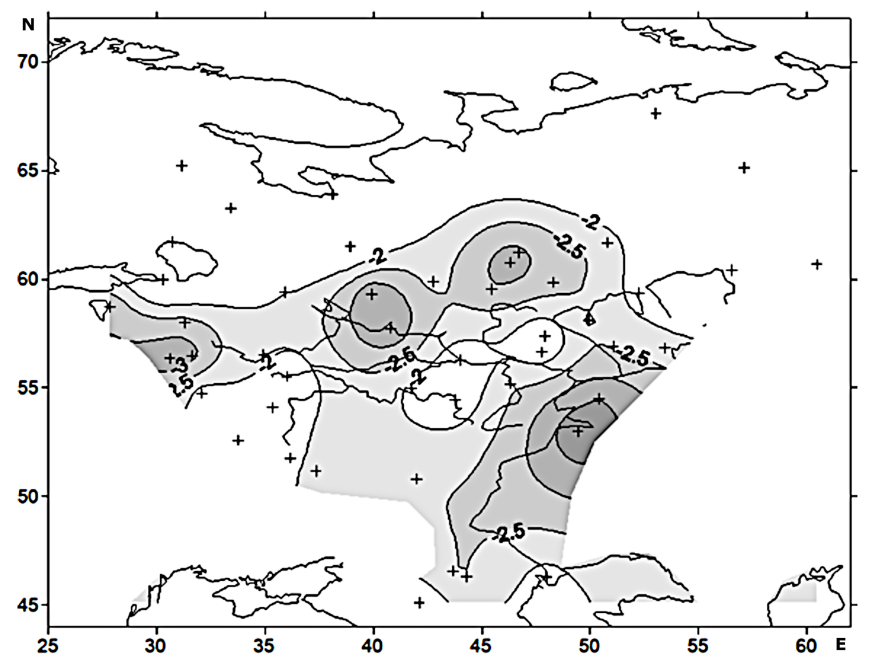

Figure 5. Spatial distribution of the Student's test for assessing the discrepancy between the average values of the potential evapotranspiration coefficients $E_{0} / P$ for droughts and norm (a) and for excessive moistening and norm (b).

to the formation of severe droughts and excessive moistening of the territory. For this purpose, the stations with $t>2$ have been selected. For droughts, the number of such stations is $n=35$, for excessive moistening $-n=24$. The coefficients of determination between the coefficient of potential evapotranspiration and precipitation and potential evapotranspiration have been calculated. The following results have been obtained: the key factor in the formation of droughts is a decrease in the amount of precipitation ( $73 \%$ contribution), a decrease in potential evapotranspiration being the one in the formation of excessive moistening ( $91 \%$ contribution).

\section{Conclusion}

The article discusses the features of interannual variability of moistening (potential evapotranspiration, precipitation, moisture coefficient) over the European Russia for 1966-2017. The most physically based and modified Budyko method has been used to assess the potential evapotranspiration. A series of original maps of moistening components has been constructed, a number of maps for the ER being constructed for the first time. The presence of positive trends in the annual values of potential evapotranspiration has been established, the distribution of which having a patchy charac- ter. The maximum trends are observed mainly in the south-western ER. The distribution of positive trends in precipitation is also patchy, with maximum estimates of $3.7 \mathrm{~mm} /$ year for the Syktyvkar region. Due to the similar nature of trends in potential evapotranspiration and precipitation, there takes place the smoothening in the potential evapotranspiration coefficients $E_{0} / P$, resulting in their trends being insignificant over most of the ER.

For the first time in a long period, the interannual variation of moistening components in the ER has been considered and the presence of powerful anomalies in the form of extreme droughts and excessive moistening has been shown. Their formation is due to the complete coincidence of significant positive anomalies of potential evapotranspiration and negative anomalies of precipitation in most of the ER, and vice versa. The assessment of unevenness of spatial distribution of severe droughts and excessive moistening over the territory has been carried out. The most powerful droughts are shown to be concentrated mainly in the forest-steppe zone (in the areas of Krasnoslobodsk and Elatma). Excessive moistening is predominantly patchy in nature and is practically absent in the northern ER. The predominant factor in the formation of droughts is a decrease in the amount of precipitation, a decrease in potential evapotranspiration being the one in the formation of excessive moistening. 
Acknowledgments. The work has been carried out within the framework of the Government Contract FSZU2020-0009 "Study of physical, chemical and biological processes in the atmosphere and hydrosphere under conditions of climate change and anthropogenic impacts".

\section{References}

Bedritskii, A. I., A. A. Korshunov, M. Z. Shaimardanov (2009), The bases of data on hazardous hydrometeorological phenomena in Russia and results of statistical analysis, Russ. Meteorol. Hydrol., 34, 703-708, Crossref

Budyko, M. I. (1971), Climate and Life, 470 pp. Gidrometeoizdat, Leningrad. (in Russian. English publication, D. H. Miller (ed.), 1974, 508 pp.)

Bulygina, O. N., V. N. Razuvaev, et al. (2020), The bases of data on hazardous hydrometeorological phenomena in Russia and results of statistical analysis, Description of data set of monthly precipitation totals from Russian stations, RIHMI-WDC, URL: http://meteo.ru/ english/climate/descrip7.htm.

Cherenkova, Ye. A. (2013), Quantitative evaluation of atmospheric drouht in Federal District of the European Russia, Izvestiya RAN Seriya Geograficheskaya, 6, 76-85. (in Russian)

Cherenkova, E. A., N. A. Shumova (2007), Potential evapotranspiration in quantity indicators of climate, Arid Ecosystems, 13, No. 33-34, 55-67. (in Russian)

Frolov, A. V., (ed.) (2014), Second Assessment Report of Roshydromet on Climate Changes and Their Consequences on the Territory of the Russian Federation, 1003 pp. Roshydromet, Moscow. (in Russian)

Gidrometeoizdat (1976), Recommendations for Calculate of Evaporation from Land Surface, 96 pp. Gidrometeoizdat, Leningrad. (in Russian)

Gordeeva, S. M., V. N. Malinin (2018), On predicting annual runoff of large rivers of european Russia based on decision trees method, Proceedings of the Russian State Hydrometeorological University, 50, 53-65. (in Russian)

IPCC (2013), IPCC Climate Change 2013: The Physical Science Basis. Contribution of Working Group I to the Fifth Assessment Report of the Intergovernmental Panel on Climate Change, 1535 pp. Cambridge University Press, Cambridge, United Kingdom and New York, NY, USA.
IPCC (2019), On predicting annual runoff of large rivers of european Russia based on decision trees method, Climate Change and Land an IPCC special report on climate change, desertification, land degradation, sustainable land management, food security, and greenhouse gas fluxes in terrestrial ecosystems, IPCC, https://www.ipcc.ch/srccl/.

Malinin, V. N. (1994), The problem of Forecasting the Level of the Caspian Sea, 160 pp. RSHI Publ., Saint-Petersburg. (in Russian)

Malinin, V. N., S. M. Gordeeva, D. A. Gur'yanov (2014), Simple parametric humidification model of north-west Russia for the conditions of modern climate change, Proceedings of the Russian State Hydrometeorological University, 36, 35-49. (in Russian)

Malinin, V. N., S. M. Gordeeva (2019), Effect of Moisture Exchange in the Northern Atlantic on European Russia Moistening and Annual Volga Runoff, Water Resources, 46, No. 3, 466-479, Crossref

Popova, V. V., E. D. Babina, A. G. Georgiadi (2019), Climatic Factors of the Volga Runoff Variability in the Second Half of 20th - Early 21st Centuries, Izvestiya $R A N$. Seriya Geograficheskaya, 4, 63-72, (in Russian $\longdiv { \text { Crossref } }$

Rybanova, A. Yu., A. A. Fokicheva, et al. (2019), Economic value of information activities of the Hydrometeorological Service, Proceedings of the Russian State Hydrometeorological University, 56, 38-49, (in Russian) Crossref

Schwer, Ts. A. (1976), Precipitation on the USSR Territory, 302 pp. Gidrometeoizdat, Leningrad. (in Russian)

Smirnov, N. P., V. N. Malinin (1988), The Atmosphere Water Balance as a Hydrological Problem, 189 pp. LSU Publ., Leningrad. (in Russian)

United Nations (1994), Convention to Combat Desertification, 71 pp. Chatelaine, Geneve.

Zolotokrylin, A. N., T. B. Titkova, E. A. Cherenkova (2014), Humidification of dryland of the europian Russia: the present and future, Arid Ecosystems, 20, No. 2, 5-12, (in Russian) Crossref

Zubenok, L. I. (1976), Evaporation on the Continents, 264 pp. Gidrometeoizdat, Leningrad. (in Russian)

\section{Corresponding author:}

S. M. Gordeeva, Russian State Hydrometeorological University, St.-Petersburg, Russia. (gordeeva@rshu.ru) 